\title{
On the Electrical Installment Technology of 10kV Switching Room
}

\author{
Zheng Weiliang, Dai Fangxin, Jiang Hua
}

Yingkou Power Supply Company of National Grid Liaoning Electric Power Co., Ltd

jkweiz@sina.com

Keywords: 10kV Switching Room; Electrical Installment

\begin{abstract}
Along with scientific and technological progress, the modern multi-use office buildings of various kinds have risen straight from the ground; under such circumstances, the installment of $10 \mathrm{kV}$ switching room has been needed by the users. Besides, to guarantee the demands of grid electricity, the $10 \mathrm{kV}$ switching room is installed in many residential buildings and factory buildings. As an important link of the power supply and distribution system, the installment technology of $10 \mathrm{kV}$ switching room will exert direct influence on the quality of the whole project.
\end{abstract}

\section{Introduction}

Both the modern office building, plants and residential buildings necessitate the $10 \mathrm{kV}$ switching room, which can guarantee the successful transmission of grid electricity to the designated intermediate transit point for the users. Therefore, the electrical installment of $10 \mathrm{kV}$ switching serves as an important link in electricity supply and distribution system of modern electric power construction. At the meantime, the electrical installment of $10 \mathrm{kV}$ switching room is of prime importance and vitality to the image of the whole project. This paper offers a detailed introduction to construction technique, including the installment of foundation steel and high pressure cabinet, the specific method of cable laying and wiring and the precommissioning examination of the switching room.

\section{The Detailed Operational Requirements of Electrical Installment of Switching Room}

The operational process of electrical installment of switching room mainly includes land construction, installment of high-low voltage switch cabinet, installment of foundation steel, cable laying, bus structure and crane span structure construction and installment of grounding grid. The specific operational requirements for each mounting point is listed as:

\section{Requirements of Land Construction}

In the process of land construction reserve, it is important to guarantee that the traverse range balance of the foundation steel should meet the relevant electrical policies and guidelines, examine and verify the specific location of high-low voltage switch cabinet and buildings as well as the embedded part and recognize whether these contents meet the requirements, for example, the accurate location of the embedded parts, the appropriateness and consistency of the high-low voltage switch cabinet size.

\section{Installment of Foundation Steel}

After the manufacturing of the foundation steel on construction site, the level shall be used to measure the progress of searching for balance. First, it is demanding to calculate the highest elevation point of structural steel under the natural conditions and then mark this point. Then other space joint and this elevation shall be arranged together. After the arrangement of all the elevation, the reexamination shall be conducted. Finally, the firm fixing is realized through full-length welding and level used for error measurement so as to ensure that the error is controlled within $1 \mathrm{~mm}$. With respect to structural steel grounding, the galvanized flat steel and grounding main line shall be connected to ensure that the ground resistance meet the code requirements that have been set. 


\section{Manufacturing, Fixing and Grounding of Foundation Steel}

\section{1) Manufacturing of Foundation Steel}

Considering the weight of $10 \mathrm{kV}$ power distribution cabinet, the installment of foundation steel is subject to field fabrication according to the design drawing to enhance the stability performance of power distribution cabinet, conform to the design requirements of the $10 \mathrm{kV}$ power distribution cabinet, adjust the design size of foundation steel according to the actual condition and avoid the loss caused by inconsistency between design and actual conditions. In the process of placing the box iron, the distance between the two columns of plates is vital to the installment of bus-bar crane span structure; for this reason, special attention shall be paid to the size.

\section{2) The Fixing of Foundation Steel}

In the fixing of foundation steel, level and total station are utilized for repeated precision measurement to avoid the errors caused by measuring technique, reduce the error to the minimum level and realize the precise fixing of foundation steel.

If without special requirement, the highest elevation under natural condition can be measured. Other elevations should be fixed at the same position as this elevation. Considering the design beauty, the soldering iron is placed under the power distribution cabinet. Under such circumstances, the constructors should flexibly adjust the indoor horizon and mark all those $2 \mathrm{~cm}$ higher than the elevation, which are the elevation position for the fixing of foundation steel.

\section{3) Grounding of Foundation Steel}

The grounding design of foundation steel requires that at least two parts of the base of foundation steel should be grounded. With respect to material selection, the $50 \times 5$ galvanized flat steel is selected in strict accordance with the design criteria. To ensure the security of using foundation steel, special attention should be paid to the welding of the inside foundation steel apart from the compact contact between foundation steel and cabinet. Galvanized bolt is suggested to be used.

\section{Requirement for the Installment of High-low Voltage Switch Cabinet}

Before the installment of high-low voltage switch cabinet, it is suggested to conduct overall reasonable and scientific detection of the form of the switch cabinet, install on site after it is confirmed to meet the standards and spread out on one side by taking the position set in the design sample manuscript as the standard. The high-low voltage switch cabinet is placed above the structural steel. It is worth-noticing that sufficient space shall be left between each disc. Due to the incompatibility of the gap of structural steel, the last one or few discs are allowed not to be installed above the structural steel.

\section{Requirement for Bus Structure and Crane Span Structure Construction}

In the process of installment of bus structure and crane span structure construction, the grounding of bus structure must be made in conformity with the requirements that have been set and the space between crane span structure in line with the standards. The non-standard crane span structure, shelling and the prolonged cross arm of boom bracket are prohibited. The expansion joint and anti-sway bracket shall be arranged according to the regulations.

\section{Requirements for Cable Laying}

The cable laying shall ensure the orderliness of laying with the interlaced arrangement of cables prohibited. The cable laying should be firmly fixed and marked. If without circuit labeling, it is advisable to mark the cable type, specification and the site of laying and location of arrival. Meanwhile, the number and labeling of the cable used in parallel circuit shall be guaranteed. The labeling must be kept in high definition and not easy to fall out. The corrosion prevention shall be carried out by following the same specification. The cable laying within the pipeline is also undertaken in strict accordance with the drawing. It is prohibited to insert AC single core cable into 
the steel pipeline. The directly inbuilt cables should also meet the preset requirements and be subject to the test of hidden project before undergoing backfill. In other words, the backfill will be applied only when it undergoes successful test. Besides, the backfill shall be laid tightly one layer after another. The circuit labeling of cable laying is also required to be in consistence with the actual circuit. The two ends of the cable must have clear and visible labeling, which is in line with that of the system.

\section{$10 \mathrm{kV}$ Control Measures for the Construction Quality of Electrical Installment of Switching Room}

\section{Quality Control Measures in the Preparation Link}

In the preparation link of electrical installment of $10 \mathrm{kV}$ switching room, it is required to review the schematic diagram of the switching room first; the relevant design department must also offer the final inspection and review of the distribution system provided by the relevant design department. When the power distribution equipment meets the requirement, they are allowed to be integrated into the switching room, undertake the task of inspecting whether the field data are complete and arrange the special personnel for the management of data and equipment. Before the installment of electrical equipment, it is of great importance to formulate the corresponding construction scheme to ensure that the equipment is successfully installed according to the construction scheme.

\section{Quality Control Measures in the Construction Process}

In the process of installing electrical equipment, the major tasks involved include the installment of high-low voltage switch cabinet, the threading of copper bar in the cabinet, threading laying, installment of high-low voltage cable tray and the installment of air hose and busbar. Therefore, in the whole project installment process, it is demanding to conduct effective control over the project quality and ensure the safety and reliability of electrical installment. The specific quality control measures must contain the following parts; First, the construction of electrical installment project must be carried out in accordance with the standardized process; at the meantime, the electrical installment and construction quality are guaranteed to meet the expectant requirement; second, prevention must be made for the recurring issues in the process of electrical installment project, which shall be properly handled in a well-targeted and timely manner; at last, it is necessary to strengthen the control of the progress of electrical equipment installment, take into consideration the issues popping up in the equipment installment process and effectively arrange the construction sequence.

\section{Preliminary Debugging Work and Quality Control Measures}

After the installment, the inspection is carried out before the debugging because the high-voltage system has higher requirements for insulation. Usually, even the minor mistake will cause the damage to the equipment in the debugging process. However, in the process of inspection, floor and cable duct are all brought under inspection to avoid the nearby rubbish dumps, the sundries or dust in the high voltage cabinet. Meanwhile, it is essential to conduct detailed inspection to check if the high-voltage cabinet and the part between cabinet door and body are grounded. The debugging will not begin unit the completion of the inspection work.

\section{Conclusions}

In one word, the electrical installment of $10 \mathrm{kV}$ switching room must start with the details of installment process. The installment of high-voltage cabinet hinges on the security and excludes all the influential factors posing threat to the security of switching room. This paper begins with the details and then offers a detailed introduction to the installment (manufacturing, fixing and grounding) of foundation steel, installment of high-voltage cabinet (inspection, installment), installment of busbar (inspection and pre-assembly, installment), cable laying and grounding (high voltage cable, controlling cable) and the preliminary work of inspection. In one word, only by 
improving the electrical installment technology of $10 \mathrm{kV}$ switching room will the electrical installment of $10 \mathrm{kV}$ switching room be better carried out.

\section{References}

[1] Li Chunyan. On the Electrical Installment of 10kV Switching Room [J]. Guangdong Building Materials, 2008 (10).

[2] Wu Haitao. Construction Technical Analysis of Electrical Installment of 10kV Switching Room [J]. Mechanical and Electrical Information, 2014.

[3] Li Yanji, Lin Shiwu, Wang Fan. Analysis of the Maloperation Analysis of Outgoing Feeder of Railway 10kV Switching Room [J]. Railway Locomotive Vehicle, 2012 (4).

[4] Cai Jianting. Research on Electrical Installment Technology of Switching Room [J]. Science Review, 2012 (17).

[5] Zuo Qiandong. The Relaying and Setting Protection and Design of 10kV High-tension Distributing Line in the Switching Room of Enterprise User Terminal [M]. Urban Construction Theory Research: Electronic Version, 2011 (33): 36-37. 